\title{
Analyzing Financial Models on Water Supply Project in Thanh Tri District, Hanois
}

\author{
Ersi Liu \\ International Business School \\ Yunnan University of Finance and Economics(YUFE) \\ Kunming, Yunnan Province, China \\ liuersi907@126.com
}

\author{
Lu Thi Toan* \\ dept. name of organization \\ line 2-name of organization, acronyms acceptable \\ line 3-City, Country \\ line 4-e-mail address if desired
}

\begin{abstract}
Today, clean water is an urgent issue that attracts the attention of all communities around the world. Most of the freshwater sources in the world in general and in Vietnam, in particular, are contaminated at different levels of severity. Before that situation, Vietnam has promulgated the Law on Environmental Protection and many legal documents on the supply of clean water to the people. However, many rural areas are very difficult for drinking water. Thanh Tri district is the southernmost district of Hanoi. In recent years, Thanh Tri has been experiencing rapid urbanization. As a city in the south of the capital, Thanh Tri Many sources of pollution of the capital such as sewage, waste gas. Therefore, over the past years, the leaders from the central to the city have paid attention to clean water sources for the Thanh Tri people. However, compared to the population of more than 230,000 people, that amount of water is still lacking. In order to meet the demand for clean water for people in Thanh Tri district, there will be many mini water plants of different sizes in the future. The BOT project has been widely applied in the transportation of Vietnam. Through study, analysis researcher found the project is perfectly suitable to apply and bring high results in the construction of clean water supply project for Thanh Tri District.
\end{abstract}

Keywords-financial models; water supply project; Thanh Tri District; BOT

\section{INTRODUCTION}

\section{A. Background and Rationale of the Study}

At present, clean water is a hot issue that attracts the attention of all communities worldwide, especially in developing and underdeveloped countries. Most of the freshwater sources in the world in general and in Vietnam, in particular, are contaminated at different levels of severity.

A 2006 study released by the United States' International Panel on Population Studies (PAI) said that by 2025, one out of every three people in the world would be living in extreme stress or very scarce on water.

In 2004, the research findings on "Sustainable Water: Population and Future of Renewable Water Supply" show that more than 350 million people live in stressed or water-scarred countries (per year). each person is under $1700 \mathrm{~m} 3$ of water).
The number of people who fall into this situation will increase by 8 times by 2025, from 2.8 billion to 3.3 billion, equivalent to nearly half of the world population.

We know that contaminated drinking water is a major source of disease, affecting people's health and well-being, resulting in child malnutrition and long-term effects. the following system.

Thanh Tri district is a southernmost district of Hanoi, a lowland area, with an average rainfall of 1600-1800 mm. Thanh Tri has many small rivers flowing like Red River, Nhue River, Kim Nguu River.

With many different sources, up to now, Thanh Tri district has built a concentrated water supply system, excluding Van Dien water plant, with a total capacity of $7900 \mathrm{~m} 3$ / day. These systems have partially solved the water demand of local people in the district.

However, compared to the population of more than 230000 (2017) people, that amount of water is still lacking. There are still 8 "white" communes without water supply system. In densely populated communes, a mini plant is not enough. To meet the demand for clean water for people in Thanh Tri district, there are 13 mini water plants of different sizes in the future.

Thus, the water supply for the remaining 8 communes of Thanh Tri district in the next period is very necessary.

To build an effective, successful water supply project, the first and most important thing is to find the appropriate financial model, so I would like to study and analyze the following two financial models to find the model Appropriate and applicable to Thanh Tri-District.

\section{B. Objectives of the Project}

Construct two financial models in Thanh Tri district

Compare and find the appropriate financial model

At the same time, assume the parties involved, find a bank for my project, etc.

*Corresponding author 


\section{LITERATURE REVIEW}

\section{A. The Importance of Clean Drinking Water}

We all know that water is a special kind of resource Important is an essential component of life and the environment, determines the existence, the development of each country. However, throughout the world, many still there is no safe and adequate water to meet the most basic needs their. Water resources are being threatened by wastes and pollution, by ineffective use, because of change of land use purpose, rather global climate change and many other factors.

Freshwater though only accounts for $1 \%$ of the world's water but it is vital to the survival of the human and the natural world. Water plays a particularly important role in most broadcasting activities Socio-economic development in each basin: Water supply for a living, Water supply for industry and services, Irrigated agricultural land etc...

Vietnam is an agricultural country, Vietnam is now a second largest exporter of rice in the world, water used much for agriculture. According to calculations, in 1985 used 41 billion $\mathrm{m} 3$, accounted for $89.9 \%$ of total water consumption in the country, in 1990 used 46.9 billion m3, accounting for $90 \%$ and about 60 billion $\mathrm{m} 3$ in 2000 . So far, the whole country has There are 75 large and medium irrigation systems, many small irrigation systems with total Fixed asset value is about 60,000 billion VND (excluding land and public value People's contribution).

It is increasingly clear that water is a particularly important resource for life, is an essential condition for existence and development not only for natural systems but also for socioeconomic systems and Humanities. Water resources must be seen as a commodity economic and social special.

\section{B. Financial Analysis of Investment Projects.}

The template is used to format your paper and style the text. All margins, column widths, line spaces, and text fonts are prescribed; please do not alter them. You may note peculiarities. For example, the head margin in this template measures proportionately more than is customary. This measurement and others are deliberate, using specifications that anticipate your paper as one part of the entire proceedings, and not as an independent document. Please do not revise any of the current designations.

Financial analysis is an important economic content for assessing the feasibility project financially by:

Considering the need and assurance of financial resources for the effective implementation of the investment project (determining the size of the investment, the structure of the types of funds, the sources of funding for the project).

Review the situation, results and performance of the project in terms of economic accounting of the project implementation unit. This means considering the costs that will have to be incurred from the drafting until the end of the project to take into account the benefits that the project implementing unit derives from the project implementation.
Financial analysis is also the basis for socio-economic analysis.

\section{Socio-economic Analysis of the Project}

1) The necessity to consider the socio-economic aspects of the investment project

We all know that in a market economy there is a macroregulation of the house water, all production, and business activities, including investment activities. Considering from two angles:

- Investors.

- Economy

And the fact is, not every project is profitable to have created good effects on the economy and society. The benefit of economic- the social investment project is the difference between the benefits that the economy and the commune.

This is comparable to the contributions that the economy and society have given in the real world present the project.

The benefits to society are the project's response to the realization of the common goals of society, of the economy. Answers This application can be considered qualitative as meeting the objectives of of-of economic development, serving the implementation of the policies of the HouseWater, contribute to environmental pollution, environmental improvement or measurement.

By quantitative calculations such as the increase in budget revenues, the increase in a number of employed persons, foreign currency increase, and increased opportunity benefits due to a reductiondisease for the people ...

Thus, the socio-economic analysis of the investment project is a purposeful comparison between the cost society has to pay for the use of resources. The best available and the benefits generated by the project for the whole economy.

Thus, socio-economic analysis of a project is necessary and must be analyzed in a clear and thorough manner.

2) Methods for assessing the socio-economic benefits of project implementation

When considering the socio-economic benefits of a project, all direct and indirect costs associated with the implementation of the project must be taken into account. project (full cost sufficient), all direct and indirect benefits (full benefits) earned by the project.

To determine the full benefits and costs of investment projects, financial reports must be used, calculating inputs and outputs at social prices (prices hidden or shadow price, reference price). Do not use market prices to calculate costs and socio-economic benefits.

In fact, fresh and clean water sources of the world in general and Vietnam, in particular, are polluted at different levels of severity.

Meanwhile, the rate of population growth is increasing and therefore the demand for clean water for a living is becoming more pressing than ever. Thus, there must be more and more 
occurrences of treatment stations and provide clean water for people to serve the needs of dark life their minimum.

\section{BOT in Vietnam}

\section{1) Concept}

Under the provisions of Clause 17, Article 3 of the Investment Law, the term BOT is defined as follows: BOT contracts are forms of investment signed between competent state agencies and investment for construction, dealing in infrastructure works for a certain period of time; The investor will transfer the project to the State of Vietnam

\section{2) Characteristics}

The BOT contract has the following basic characteristics:

Legal basis: Investment activities or investments in business capital are conducted on the basis of contracts signed between investors and the State (through competent state agencies). Investors directly conduct business activities with the legal status of their own in accordance with the content of the agreement in the contract. Investors must comply with the law on investment in Vietnam and other relevant legal documents.

Regarding the subject of the contract: The subject participating in the negotiation and signing of the project contract consists of one party being the competent State body of Vietnam and one party is the investor.

The object of the contract: The object of the form of investment under the BOT contract is the infrastructure.
A form of the contract: The form of the contract in accordance with the provisions of the Civil Code and related documents, the form of the project contract is made in writing.

Contents of the BOT: Any contract is an agreement on the rights and obligations that each party must perform in the contract for the benefit of the other party. In the BOT contract,

including the agreement on the rights and obligations of the investor and the State relating to the construction, business, and transfer of the project to the State of Vietnam.

3) The formation and development of the provisions of the law on investment under the BOT contract

In 2005, the State promulgated the Law on Investment, which is applicable to all investors in all industries and fields not banned by law, especially encouraging investment projects in the field of construction. Basically, to create modern and synchronous infrastructure in service of the industrialization needs of the country. Accordingly, the forms of investment under the BOT, BTO and BT contracts should be uniformly stipulated in the law on contents and forms. Therefore, on May 11, 2007, the Government issued the BOT, BTO and BT Investment Regulations applying uniformly to domestic and foreign investment in accordance with Decree 78/2007 / ND$\mathrm{CP}$. Guide investment in such forms.

On November 27, 2009, the Government issued Decree $108 / 2009$ / ND-CP on investment in form of Build-OperateTransfer (BOT) contract.

E. Two Financial Models 


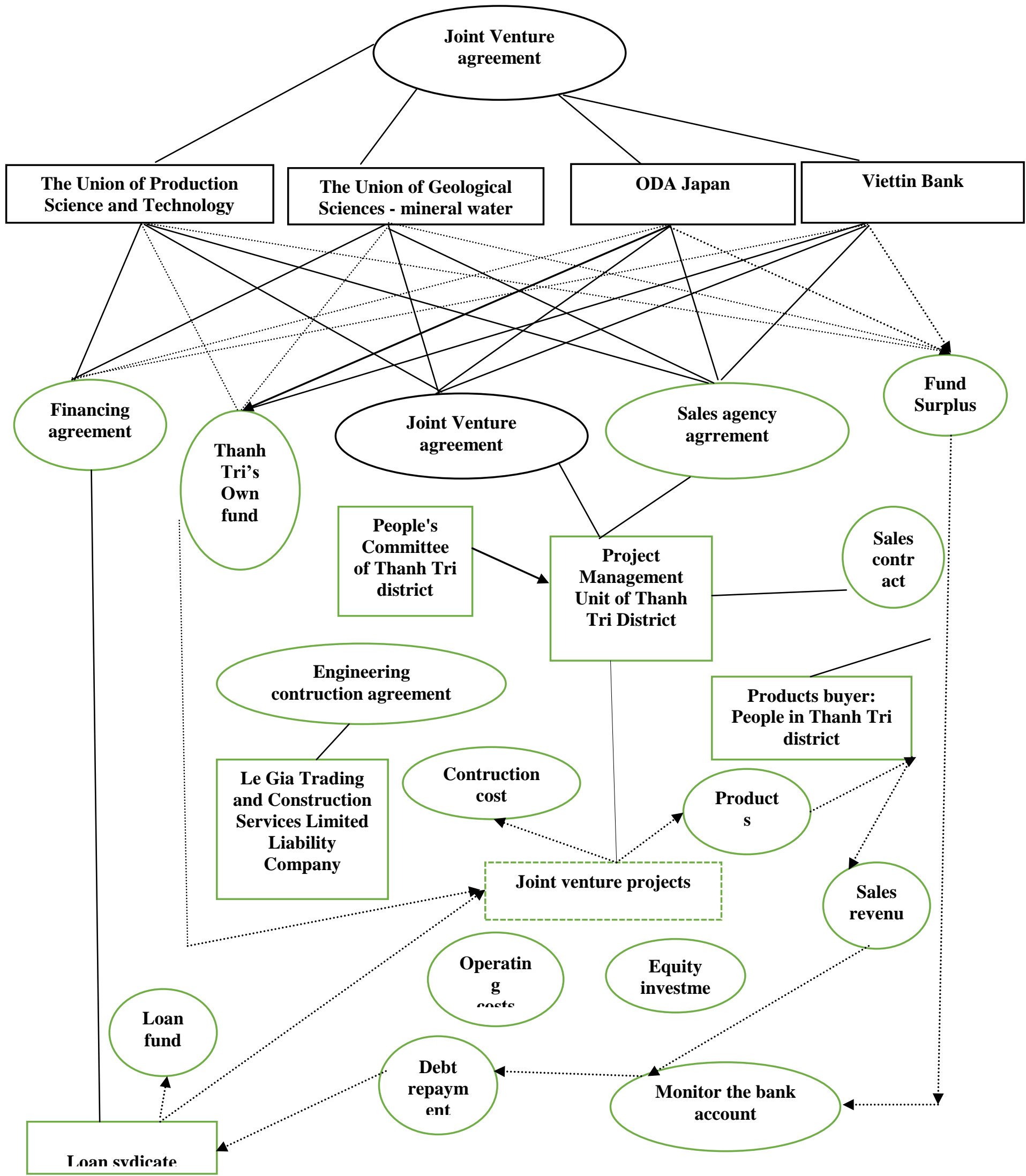

Fig. 1. Investor Arranged And Shared Responsibility Of Market Funding Process 


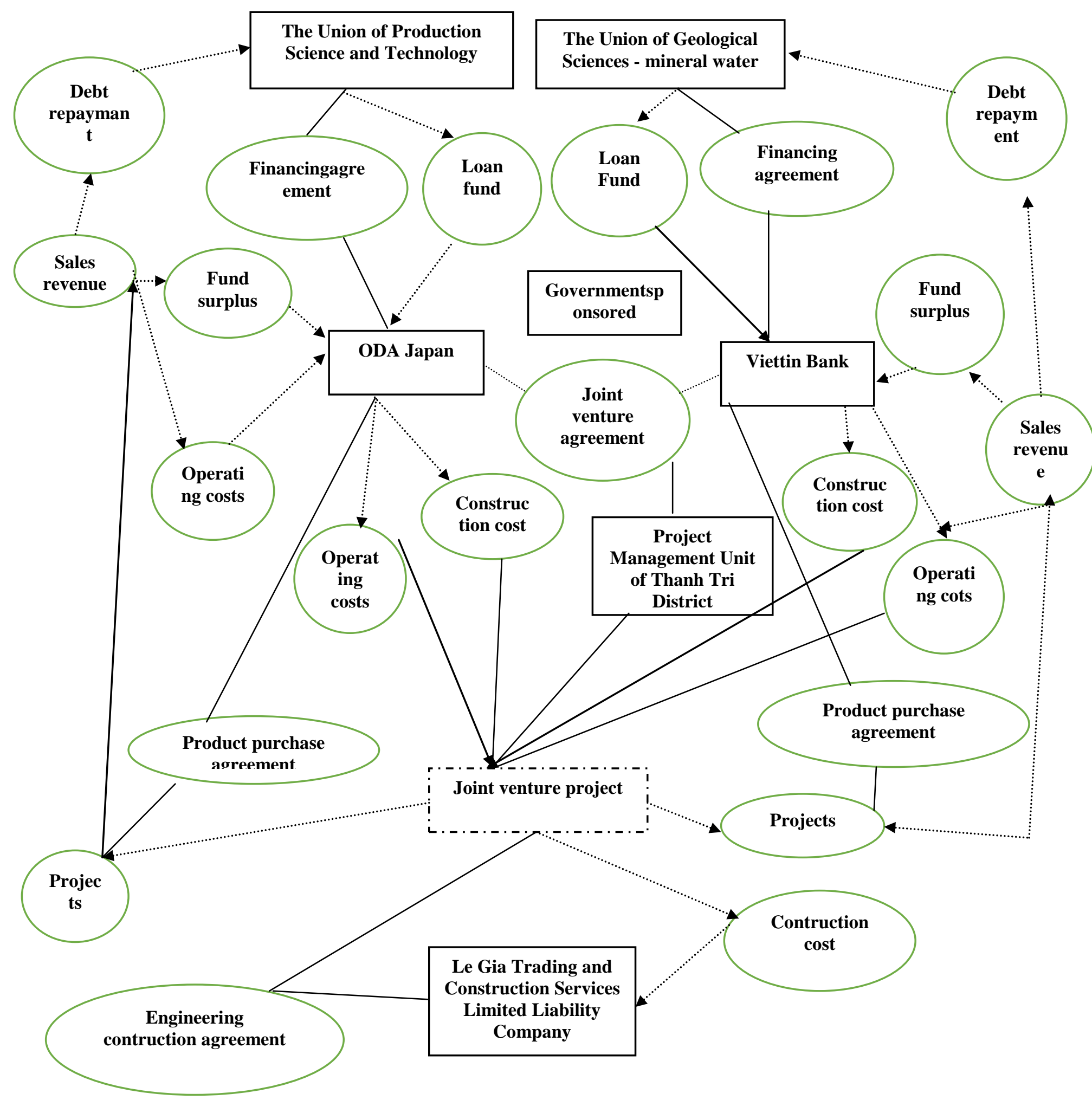

Fig. 2. Investors Independent Financing Arrangements And Assume Responsibility For Their Market Funding Process 


\section{RESEARCH METHODOLOGY}

A. Status of Water Supply System in Thanh Tri District, Hanoi

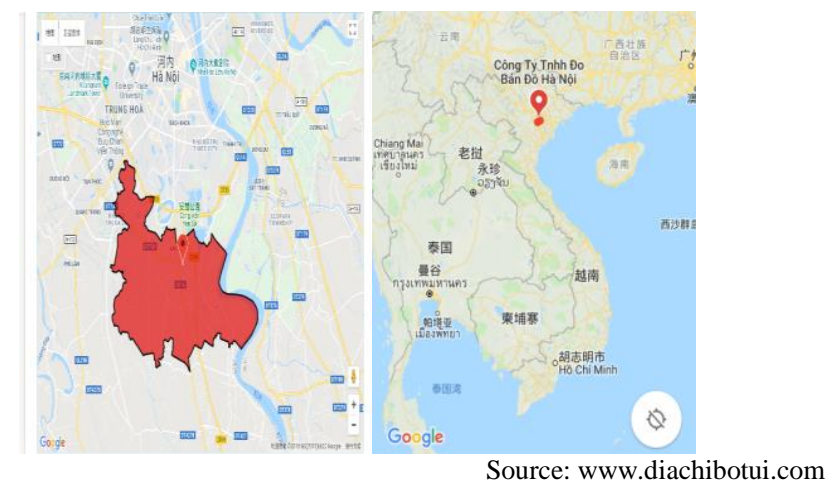

Fig.3. Map of Thanh Tri district

\section{1) Drainage system - environmental sanitation}

\section{a) Rainwater drainage system}

There are two different drainage systems in Thanh Tri district:

\section{b) Drainage system for the inner city}

This system consists of river systems, lakes, technical facilities that drain water from the inner city flowing through the district and then into two large rivers: the Red River and Nhue River.

There are also other connected projects: Yen So pumping station with a capacity of $60 \mathrm{~m} 3 / \mathrm{s}, 3$ pump stations located in Cau But with a capacity of $3 \mathrm{~m} 3 / \mathrm{s}$.

\section{c) District drainage system}

Canal system: There are 8 drainage ditches in the whole district spreading across the district to carry out drainage work for residential areas, for irrigation.

Reservoir: scattered throughout the district with a total area of 769 hectares is currently used to fish.

Pumping station system: There are 6 main water pumping stations mainly serving for irrigation works with a total capacity of $90,000 \mathrm{~m} 3 / \mathrm{s}$ concentrated mainly in the south of the district such as Dong My pump station, Sieu pumping station.

These systems are responsible for draining the entire district. Therefore, when building residential areas in the district should combine the drainage system.Urban water with an irrigation system of the district to not affect the surrounding area and agricultural production.

\section{d) Drainage system}

Contaminated domestic wastewater is discharged from septic tanks and industrial wastewater is discharged directly into the stormwater drainage system.

\section{2) Economy}

At present, the economy of Thanh Tri is in the momentum of strong development and diversification of industries. Thus, through the above analysis, the surface water in most communes in Thanh Tri district is polluted, some places are heavily polluted. So if so People living, producing with this surface water, the infection of intestinal diseases and other dangerous diseases such as cancer ... is unavoidable.

Therefore, the construction of water stations to provide clean water for living and production of the people is very necessary and is a top concern of the People's Committee of Thanh Tri District as well as of Hanoi.

Current status of the current water supply system in Thanh Tri. At present, the people of Thanh Tri district are using the following forms of water supply for a living:

$\varnothing$ Tap water is supplied to each house or public house. Form this is granted to the urban residential areas of Van Dien Town, the immediate area Water plants and suburban areas such as Vinh Tuy, Thanh Tri, Tuong Mai, Giap Bat, Khuong Dinh, Trieu Khuc ...

$\varnothing$ Well water wells, wells in dike areas and hamlets.

$\varnothing$ rainwater tanks in all places.

$\varnothing$ Acid filter in the area outside the Red River.

\section{B. Analyze the Applicability of Two Financial Models in Thanh Tri}

Design financing mode is one of the key tasks of project financing. The direct financing model refers to a method by which the project investor directly arranges the financing of projects and directly assumes the corresponding responsibilities and obligations in the financing blackout. When the investor's own company's financial structure is sound and reasonable, this model is compared. Applicable is the simplest kind of financing model. There are two main operational ideas for its structure arrangement:

1) Investor Arranged And Shared Responsibility Of Market Funding Process

Investors are faced with the same loan bank and direct market financing arrangements. In this method of operation, all investors face the same loan bank or loan syndicate. Arrange for financing, and establish a project management company to act as a unified agent to sell project products and share market responsibilities.

2) Investors Independent Financing Arrangements And Assume Responsibility For Their Market Funding Process

In this operation idea, project investors still directly arrange to finance, but each investor arranges to finance for their respective lenders according to their own financial status, and each project is funded by various projects. Investors (rather than project management companies) are responsible for organizing a corresponding share of product sales and debt repayments.

Investors independently arrange to finance and assume market sales responsibility. Features of Direct Financing Model:

Flexible choice of financing structure and financing method 
The debt ratio arrangement is more flexible

It can flexibly use the sponsor's reputation in the business community.

Inadequate: mainly manifested in the complexity of designing the financing structure as a limited recourse

\section{3) Conclusion}

Through the analysis of the two characteristics of the two models, I found that the two models can be flexibly used and one of the simple, easy to use and easy to apply models. And the economic conditions in Vietnam, I see both models can be applied in this country. As I go deeper analysis, I find the model "Investors independent financing arrangements and assume responsibility for their market funding process. "Better fit in Thanh Tri because if you apply this model, investors will work independently and be responsible for their own work, the good side of the Vietnamese is much, but from my personal point of view, the Vietnamese have the disadvantage is very high solubility, teamwork as well as self-ability is not high, the phenomenon This is one of the reasons why the speed of Vietnam's economy has not developed rapidly. Therefore, when applying this model, participants will be self-aware, responsible, More intelligent, from which to set higher efficiency.

\section{DATA ANALYSIS AND RESULT}

\section{A. Forecast on Clean Water Demand of Thanh Tri District}

Based on the master plan for construction and analysis of the actual situation of Thanh Tri district at the end of 1997, the 1998 plan for the commune identified the water supply solution in Thanh Tri district as follows:

The region borders with the inner city to Phap Van, where the pipeline has been passing through the use of domestic water mainly by the Tuong Mai, Ha Dinh, Phap Van, Nam Du, etc. granted.

Improving Van Dien water supply station to supply water for Van Dien - Ngoc Hoi town.

Small localities (Yen So, Ta Thanh Oai, Dong My, and Buoi) will build local treatment stations.

Rural areas: In concentrated residential areas, construction of local water supply stations at village and commune levels with the capacity of $500-1000 \mathrm{~m} 3$ / day. In remote areas, the sparsely populated area adopts another clean water treatment model under the rural clean water program.

Conclusion: It is necessary to have a realistic and highly feasible water supply project for the present, and I believe that the project that I presented in the following will meet the requirements.

\section{B. Introduction of Water Supply Projects for the Remaining Communes in the District Thanh Tri}

8 communes without clean water system in Thanh Tri district, Hanoi: Yen My, Dinh Cong, Duyen Ha, Van Phuc, Huu Hoa, Vinh Tuy, Linh Nam, Ngu Hiep.

\section{1) Water resource}

The water is taken from two sources, the floating water supply station from the Red River, the underground water supply to the underground water from 70 to $80 \mathrm{~m}$.

\section{2) The objective of the investment project}

This project will provide clean water for people in the district to improve their living conditions, health and promote local economic development.

\section{3) The investment efficiency of the project}

This project will provide clean water to meet the demand activities and products for the people in the district. In addition to providing clean water for health facilities, education ... need clean water living.

4) Agency in charge of investment:

People's Committee of Thanh Tri district, Hanoi.

5) Project Implementing Agency:

Thanh Tri District Project Management Board.

6) Agency for project planning and technical advice:

Developed by the Union of Science Production of Chemical Technology and the Joint Science of Geological Mineral Water

\section{Conclusion on the Net Benefits of the Project}

This project, if implemented in practice, will bring benefits Not only financially but also economically - socially, contributing to The economic development of these provinces has developed and since then has had a great impact Extremely high on the economy of the country.

D. Solutions and Recommendations to Improve the Effectiveness of the Project

1) Supply clean water for 8 communes in Thanh Tri district.

Project on building clean water supply system for the remaining 8 communes of Thanh district

It is essential to manage water supply and to protect the environment sustainably Water is not easy. With my limited ability, I would here are some suggestions and solutions to improve the efficiency of the project. This rural water supply project:

\section{2) Water supply network planning:}

According to the Law on Water Resources, Hanoi Department of Agriculture and Rural Development

To exercise the State management over water resources in their respective localities under the direct guidance of the Ministry of Agriculture and Rural Development and the City People's Committee Hanoi. To implement this task, the Hanoi People's Committee needs to assign The Department of Agriculture and Rural Development coordinates with the District People's Committee to manage and supervise Plan implementation.

Completed construction works will be handed over to local (hamlets, communes) management of exploitation and use. To work stable, long-term should nest The management apparatus 
in the form of management boards or service cooperatives the management of the Commune People's Committee. Through the summary of the experience of the water, supply stations are operating very effectively in Thanh district.

The organizational structure is organized in the form of a service cooperative (about 7-14 people, Including the chief, accountant and operator, installation, repair and security Maintenance and recording of water bill). With average water price of VND $2000 / \mathrm{m} 3$ is reasonable and consistent.

This is in line with the current economic situation in Hanoi (especially in coastal communes)

\section{3) Management of centralized water supply system:}

Concentrated village water supply stations can serve as a unit independent economy under the direct guidance of the Commune People's Committee. Management unit must are accounted for on the basis of management costs and revenue from sales of water. Expense obtained by the sale of water used in the maintenance, repair, and maintenance of the system Water supply and management costs. Pipeline installation water meters and water meters comply with the water management contract between the management unit water supply system and consumers.

\section{4) Source of funds for project implementation:}

To implement this project in the best way, it is necessary to focus on mobilizing donor organizations in all forms: nonrefundable humanitarian aid, low-interest loans or no-interest loans as a direct investment under BOT form. In order to collect and analyze, compare the data I would like to propose to the Japanese ODA organization and Vietin bank. At the same time

To mobilize people to contribute investment capital in the spirit of the State and people work together.

\section{a) Japanese ODA}

According to the State Bank of Vietnam (2016), entitled "It is possible to get Japanese ODA loans up to 2030," the Japanese ODA loan for Vietnam now has interest rates ranging from $0,1-1.4 \%$ / year; repayment period of 25-40 years; The grace period is 7-10 years. Preferential terms and conditions of Japanese loan.

"Japan will continue to provide preferential loans to Vietnam until 2030, even though Vietnam has joined the lowmiddle-income countries, although many of the donors have been vocal in reducing the loans," said Fujita Yasuo, Chief Representative of JICA Vietnam.

Thus, although from July 1977 Vietnam no longer has preferential ODA loans from other international organizations, the preferential rate of Japanese ODA loans will only slightly decrease, if Vietnam is raised This means that the average income level of Japan will continue to support Vietnam's infrastructure development through official development assistance (ODA), both in terms of support finance and technical cooperation. In fact, Japan's support in the field of infrastructure has contributed significantly to the socioeconomic development of Vietnam.

\section{b) Vietinbank Bank}

According to VNEXPRESS (2017), the title "Which four banks are lending the most BOT?" Indicates $85-90 \%$ of the investment capital BOT projects are borrowed from banks, of which $91 \%$ of outstanding loans concentrated in The four large banks, BIDV, Vietcombank, VietinBank, and SHB, accounted for $91 \%$ of outstanding loans, of which VietinBank and Vietcombank have high credit growth rates for BOT and BT projects.

According to Bui Thu Trang (Laborer Newspaper, 2018), "VietinBank lowered lending rates", emphasizing its role as The VietinBank Commercial Joint Stock Bank for Industry and Trade (VietinBank) has actively implemented the solutions and solutions of the policy of the Party, the Government and the State Bank of Vietnam. Support the development of production, business, and consumption of the government, businesses as well as people.

\section{c) Reduce costs to support customers}

VietinBank always proactively exploit the capital sources, manage the quality of growth and reduce costs to facilitate the reduction of interest rates, support businesses and people convenient access to credit, banking services, actively remove difficulties for business activities of enterprises. At the same time, the credit structure shifted towards strong growth in the fields of production - business, industry, business and governmental priority to encourage development. At present, outstanding loans of VietinBank for five priority sectors of the Government account for nearly $60 \%$ of total outstanding loans of the bank. This represents VietinBank's pioneering role in implementing the policies of the Party, Government, and State Bank as well as the leading role in providing capital for the key sectors of the economy.

\section{d) Prioritize high added value sector}

In keeping with the spirit of Resolution No. 01 of the Government dated January 1, 1818, and the direction of the Governor of the State Bank at the conference on the implementation of banking tasks on January 9 and 10, VietinBank continued to decrease. Interest rates in VND are both short and medium term for priority sectors of the Government. This is to help businesses and people access capital at the most reasonable cost, promote economic growth.

Accordingly, from January 11, VietinBank will reduce $0.5 \%$ per annum on short-term and medium-term loans in VND for priority areas for development; Particular attention should be paid to enterprises operating in the field of hi-tech agriculture; import and export; Small and medium enterprises join the chain; operating in supporting industry; Start a business with a feasible plan and feasible production project, especially for households and individual business households to upgrade into an enterprise. These are also areas of high added value, given priority to the development of the Party and the Government, creating a common motivation for economic growth.

In addition, credit programs with special preferential lending rates will continue to be applied by VietinBank for companies with good financial status, efficient production, and 
business, comprehensive use of products. products and services of VietinBank.

With these solutions, VietinBank will continue to strongly promote the production, business and consumption activities of Doanh Nhat and people, thus contributing positively to the socio-economic development. of the country.

5) The state should have priority policies for the implementation of projects To build water stations for daily life

- The State should have policies to lend without interest or interest

- For individual organizations to build water supply facilitiesclean.

- Land for construction of clean water projects transferred by the state land use rights.

- $\quad \S$ Value-added tax exemption for water construction and trading units Clean the countryside.

- Water price subsidy for rural people in the first few years (not deductibleloss, compensation for repair, operation).

6) Risk and Solutions:

As the survey, calculated above, the annual loss of water is very large (nearly $20 \%$ of total capacity), so to use water resources effectively to save costs, increase revenue and ensure sustainability For water resources exploitation, the problem is to have effective solutions to reduce the amount of water lost. In my opinion, it is necessary to have a qualified staff to participate in the management and operation of the domestic water supply system, and to educate the people. People see the responsibility and obligation to manage their own water and water, to steal water, to use the water meter seriously. They do not allow water meters to be placed in a small house for easy access. The management staff also regularly inspects and urges the strict implementation of water use regulations. each commune.

Manpower arranged to ensure the water supply system related activities depending on the scale and capacity of the station include:

- About 3 - 6 people are responsible for running the system on demand daily water use of the people as well as for other purposes.

- Between 3 and 5 people are responsible for repairing pipelines and recording fees monthly water.

- About 2-3 people have general management duties.

7) My opinion about the problems and deficiencies of the different project financing model

I think some models can be applied in practice, only those who implement the project sometimes have problems of management capacity, lack of professional knowledge, sometimes Vietnam has corruption So the effectiveness of the project will not be high.

The subject is very useful, I really like this subject. I hope to continue to study this subject to improve my knowledge.

\section{CONCLUSION}

Clean water for a living has been and will continue to be a topical issue for all countries in the world without exception. The supply of clean water to the economy is always at the top of the list.

With the high rate of urbanization, the demand for dailylife water, services, and public water are increasing. Clean water in rural areas has become an urgent issue of concern for all sectors. To achieve the goal of $100 \%$ of the population of Thanh Tri district using clean water, it is necessary to invest a lot of effort and money to renovate, upgrade and build new systems of clean water supply for farmers. villages in a scientific and effective way.

Through the above analysis, we can see the net benefits of the project is very large, it not only meet the urgent needs of clean water daily life of people living in white areas but also clean water. The major socio-economic and financial benefits contribute to the development of each commune and the overall development of the national economy.

The thesis also collected data, analyzed and solved a number of issues such as:

Find a suitable and effective financial model that can be modeled as: Investors Independent Financing Arrangements and Assume Responsibility For Their Market Funding Process in Thanh Tri.

Finding out an effective source of funds is:

+) Japanese ODA

+) Borrow money from Vietin Bank through BOT

However, due to time constraints and lack of knowledge about Project Financing, my essay is still lacking. I hope to receive feedback from teachers and readers. Thank you very much.

\section{REFERENCES}

[1] According to the data of Ha Noi Information Portal (hanoi.gov.vn) and website of Thanh Tri district (thanhtri.hanoi.gov.vn).

[2] By VNEXPRESS, the title "Which four banks are lending the most BOT?", 2017.

[3] Bui Thu Trang (Laborer Newspaper, 2018), "VietinBank lowered lending rates".

[4] ChuThuyLinh, "Study on measures to accelerate the disbursement of foreign capital to improve the efficiency of rural clean water supply project," Master thesis.

[5] 5.State Bank of Vietnam, entitled "It is possible to get Japanese ODA loans up to 2030", 2016

[6] 6. "Thanh Tri District", publisher: Hanoi Library ". 